\title{
The Race to Escape: Location-Based Escapism and Physical Activity as a Motivator in the Consumption of the AR Game Pokémon Go
}

\author{
Tal Laor \\ Ariel University, Ariel, Israel
}

\begin{abstract}
This research examines motives for engagement in Augmented Reality (AR) games. The research field examined in this study was Pokémon Go, due to the game's rapid rise in popularity. The study is based on semi-structured interviews with 35 Pokémon Go players. The theoretical framework guiding this study is the uses and gratifications theory, which deals with media consumers' uses of various media and content types to satisfy psychological and social needs (Ruggiero, 2000). Pokémon Go satisfies diverse player needs, and players' main uses of the game are related to escapism, social interaction, and challenging others. The study revealed multiple motivations for playing Pokémon Go, which were consistent with previous research, and identified two additional motivations of Pokémon Go players, which are also applicable to $A R$ use in general: increased physical activity and location-dependent escapism integrated into everyday activities outside the home. This consumption pattern is apparently part of the revolution of data accessibility online and on mobile phones, which also function as social means for satisfying needs for entertainment, escapism, and highly accessible information.
\end{abstract}

Keywords: AR game; Pokémon go; location based services; mobile; escapism

\section{Introduction}

Games are essentially a source of entertainment and a means to energy expenditure while simulating reality in various fields (Arbel et al., 2011; Yehoshua \& Parish, 2014). Game rules, emotions, curiosity, competition, and learning constitute a microcosmos of life (Arbel et al., 2011; Yehoshua \& Parish, 2014). Games engage people of all ages, in all locations and societies (Arbel et al., 2011; Yehoshua \& Parish, 2014), and people have been known to play games in the ancient human past (Saban, 1991). In contrast to earlier online games based entirely on virtual content (Gotow et al., 2010), recently developed AR-based apps offer massively multiplayer online games (MMOGs) that create fictional urban environments and combine the real physical world with the virtual world of the game. For example, in Pokémon Go in-game maps correspond to maps of the real world - outside the game. It should be noted that virtual and real environments should not be juxtaposed, as the virtual is always also real and cannot be treated as completely isolated. As Deleuze (1988, p. 123) stated, "One never commences; one never has a tabula rasa; one slips in, enters in the middle; one takes up or lays down rhythms." Deleuze of course, was not writing about AR. He referred to ethology, the study of relations between things, but his ideas are also relevant for mobile media, which are not merely about what we can capture or whether we utilize our mobile phones 24/7. Even when playing fully virtual games, players are still bound to and are responsible for events in the physical world.

Pokémon Go is one of the most popular of all online games, including games in the AR genre (Giddings, 2017; Keogh, 2017). Several studies on the use of Pokémon Go found that AR may induce behavioral changes in players and lead to many effects in various areas of life (Clark \& Clark, 2016). In view of the Pokémon Go's rapid rise in popularity, this research examines players' motivations to engage in AR games using Pokémon Go, guided by the theoretical framework 
of the uses and gratifications approach, which focuses on social and psychological needs that various media and types of content provide to communication consumers (Ruggiero, 2000).

The revolution of data accessibility online and on mobile phones motivated our study of players' unique motivations to engage in AR games. Yee (2006) found distinct motivations for playing MMOGs, including achievement, social component and immersion which includes escapism, which is a person's desire to escape from everyday worries and relax at the end of the day (Chang et al., 2018). Based on Yee's (2006) model of online gaming motivations, we posit that online games combining $A R$, data accessibility, and mobile phones will give rise to unique motivations that are related to escapism and physical activity. To explore this, interviews were conducted with Pokémon Go players who were identified on dedicated Pokémon Go forums.

Games, which constitute a microcosmos of life, are essentially a source of entertainment and a means to energy expenditure while simulating reality in various fields (Arbel et al., 2011; Yehoshua \& Parish, 2014). Games engage people of all ages, in all locations and societies (Arbel et al., 2011; Yehoshua \& Parish, 2014). Recent developments in the gaming world combine new technologies including AR. Below we review the literature on digital games, including online games and AR games.

\section{Online Games}

Online games are computer-based games that allow people to use the Internet to play games. Massively multiplayer online games (MMOGs) are not essentially different from ordinary computer games, but the shared experience and sense of community that develops between players account for MMOGs' enormous popularity today. Research on the communications between players in these games, however, offers inconsistent findings. While some researchers argue that many players tend to develop long-term social relations with other players (e.g., Seay et al., 2004), other studies have found that players' interactions are limited and tend to focus on brief communications designed exclusively to satisfy game needs (Ducheneaut \& Moore, 2004). These findings show that players of MMOGs do not tend to communicate or collaborate with each other and tend to view other players as an audience that observes their successes, rather than as friends or partners. For most players, despite a social appreciation of the people around them, the game is as an "alone but together" experience. This might be explained that the players like to be surrounded by others but not necessarily interacting with them. Direct interaction might be less appealing for players than a game designed for a spectator experience and a sense of social presence (Ducheneaut et al., 2006). Furthermore, many players refrain from sharing their real-life personal experiences with other players (Seay et al., 2004).

One important element that has been studied is people's motivations to play MMOGs. In one of the earliest studies on the topic, Bartle (1996) proposed a taxonomy of online game players based on their personality. Yee (2006) extended the model and examined whether different motivations were related to different types of player behaviors. He found 10 distinct motivation subcomponents for playing MMOGs, which he divided into three overarching components:

(a) Achievement - This component includes the following three motivations: progress (the desire to advance rapidly and reach levels to accumulate symbols of status in the game), mechanics (the desire to understand the rules of the game better and to play more effectively), and competition (the desire to defeat as many people as possible).

(b) Social - This component includes the following three motivations: socializing (the desire to help and communicate with players), relationships (using the game as a means for establishing long-term social relations), and teamwork (obtaining satisfaction from working with others).

(c) Immersion - This component includes four motivations: discovery (findings things in the game that most players are not aware of), role playing (using the game to create a character with an original background and story based on communications with others in the game), customization (the desire to customize the appearance of their character), and escapism (the desire to use the world of the game to escape reality and the problems of everyday life).

Williams et al. (2008) examined the significance of these subcomponents for players in Everquest2, an online game, and found that the main reason that respondents play the game is their desire to succeed (the Achievement subcomponent), followed by immersion in the game. The third most important reason for playing is the social aspects of the game. The researchers also found that the stronger the social or achievement components are, the greater the probability that the player will play the game more frequently. 
Online games may be used to drive various actions by adding an element of enjoyment. For example, it was found that Wii can aid rehabilitation. Mobile games that combine running or walking support health-promoting activities, while location-based games may be used to encourage students to attend cultural events or visit cultural venues such as museums and landmarks. Games have also been developed to affect tourism by influencing players' locations and encouraging greater interactions in tourist sites (Zach \& Tussyadiah, 2017).

\section{Augmented Reality Games}

The rising popularity of mobile devices that contain GPS systems enabled the incorporation of AR into mobile games. In mobile AR games, events in the real world, based on a person's physical location, interacts with the virtual information of the game. AR games are effectively an elaboration of massive multiplayer online games that create an "urban fiction" by blending the real physical world with the virtual world. In contrast to earlier online games, whose content was exclusively digital, the emergence of AR games creates a fundamental blurring of "digital" and "physical" spaces (de Souza e Silva, 2017).

Such games are based on the players' physical locations, and construct a narrative through the added content presented in the virtual world (Avouris \& Yiannoutsou, 2012; Kjeldskov \& Paay, 2007; Magerkurth et al., 2005).

An important advantage of AR games is their educational dimension. Games can develop various aptitudes and skills, such as reasoning, curiosity, creativity, collaboration, diversity of opinions, awareness of public spaces, responsibility, and efficiency. Games can create an experiential learning setting that promotes social learning and comprehension of social situations, through players' interactions with their physical environment, other players, and the virtual world of the game, (Avouris et al., 2013; Avouris \& Yiannoutsou, 2012). Some AR games were developed mainly for educational purposes and to encourage scientific understanding or comprehension of complex situations. Educational elements can also be integrated into games whose main goal is not education but are rather designed as a source of enjoyment for players (Avouris \& Yiannoutsou, 2012).

Nonetheless, many developers are concerned by various limitations of AR games. Location-based games, in which movement is considered an essential element of the game, challenge players who are used to enjoying games as passive observers. Furthermore, while AR games are considered "single-player" activities (each player operates their own mobile phone application), these games address players' needs for social interaction by calling for collaboration among players who meet in predefined physical locations. This, however, might also constitute a shortcoming for certain players, such as players who live in remote locations. In addition, game developers face serious challenges in their efforts to design games with a rapid pace and intense competition (Gotow et al., 2010; Rashid et al., 2006) that also entail location setting and dependence on cellular networks and other technological devices. As one of the most popular games that combine a sophisticated technological platform and social interactions, Pokémon Go has attracted considerable research interest.

\section{Pokémon Go}

Pokémon Go is one of the most popular games today and is a prime example of the rising popularity of the genre of AR games. The game app was launched on July 6, 2016, initially in the United States, Australia, and New Zealand, and later in other countries around the world. In this game, players are required to travel around the world in search of virtual creatures known as Pokémon, which appear in locations that appear on the game map. When a player arrives at such a location, the Pokémon will appear on his screen and the player then tries to capture it. The game uses the camera on the player's mobile phone to simulate the appearance of the virtual Pokémon in the player's physical location. The main goal of the game is to catch as many Pokémon as possible in order to accumulate points (Colley et al., 2017; Dorward et al., 2017; Pimentel, 2016).

The game's popularity soared rapidly after its launch (Hanson, 2017) and became the most popular game in the United States in its first week (The Marker, 2016), breaking records for the number of downloads in Apple's appstore (Statt, 2016). Surveys and studies on the frequency of the game's use found that players spend more time on the game than on the social media Facebook, Twitter, and Snapchat combined (Clark \& Clark, 2016). The game was ranked third in the top mobile games by popularity (Nelson, 2016) and was crowned the most popular game of 2016 (Landi, 2016). 
In a survey of Pokémon Go players, seven motivations for playing Pokémon Go were identified: work out, fun, escapism, nostalgia, maintain friendships, invest in relationships, and achievement seeking (Hamari et al., 2019; Yang \& Liu, 2017). Progressing in the game was the most frequently reported reason to continue playing (Alha et al., 2019).

Interactions with friends and family were found to have considerable impact on players' motivation to extend their playing time (Rasche et al., 2017). Players start to play the game either because they are Pokémon fans or are enthusiastic about the AR format (Rasche et al., 2017), yet trendiness was not associated with players' reuse intentions (Hamari et al., 2019).

Studies on Pokémon Go found that use of AR technologies can cause behavioral changes in players and have a considerable impact on different areas of life. For example, studies found that the game has three main effects on players: it creates a sense of community, which is manifest in ties between the player; it increases players' mobility; and it promotes physical activity (Zach \& Tussyadiah, 2017). The game encourages people to go outdoors because advancing in the game requires player to visit various sites. As a result, regular use of Pokémon Go encourages physical activity, a factor that improves player's health (Clark \& Clark, 2016; Zach \& Tussyadiah, 2017). Studies show that Pokémon Go players significantly increased the number of steps they walk every day (Althoff et al., 2016; Howe et al., 2016; LeBlanc, \& Chaput, 2017), and increased moderate to vigorous physical activity and decreased sedentary behaviors (Nigg et al., 2017). Incorporating physical activity into gameplay may be an effective method for promoting health-related outcomes in persons who are attracted to the game (Baranowski \& Lyons, 2019; Xian et al., 2017). The locations of pokestops and gyms in the game encourage people to visit important sites and monuments. Pokémon Go players have been found to spend more time outside their homes and visit places in nature that they would not have otherwise visited without the game (Dorward et al., 2017; Zach \& Tussyadiah, 2017). For example, Pokémon Go players have reported that they traveled outside their own neighborhood to play the game and are planning trips to catch Pokémon in more distant sites (Zach \& Tussyadiah, 2017). For example, in 2019, special events were held in Grant Park, Chicago, Illinois: Safari Zone, Sefton Park, Liverpool, England; and Safari Zone, Philadelphia, Pennsylvania.

Research found that players' interactions with nature can positively affect players' love of nature and nature-related activities. As a result, the game can be used to raise awareness of nature exploration and animal species in the real world (Dorward et al., 2017). Moreover, the game also has emotional effects and can help people who are challenged by interactions with others to establish ties with other players in the game environment (Fernando, 2016). It is also argued that the game can help people who suffer from social anxiety or depression (Pyae \& Potter, 2016). Enjoyment from the game has been found to be strongly related to players' positive outcomes such as reduced social differences, reduced loneliness, and improved physical health (Yang \& Liu, 2017). Pokémon Go specifically requires players to travel in order to catch Pokémon and participate in battles, which supports the assimilation of new habits and increases motivation to travel and engage in physical activity (Zach \& Tussyadiah, 2017).

The game may also have detrimental effects on players' behaviors. One of the goals of the game is to catch Pokémons and battle against others, which may encourage exploitation of and cruelty to animals in the real world in an effort to imitate the game (Dorward et al., 2017). Another shortcoming is that the pokestops and gyms in the game are located in important public sites. This feature favors people living in areas with a high concentration of public sites, while individuals living in less populated or remote areas may find it difficult to advance in the game. As a result, the game may reproduce the inequalities between individuals living in center and peripheral relations (Colley et al., 2017). The fusion between a virtual game and the real world requires players to think both about the rules of the game and the social rules and cultural norms that apply in the game's real-life locations. People who live in racial or religiously diverse areas might be limited by the number of places they can play (because they will avoid playing in sites where they are not wanted; Tekinbaş, 2017).

The main adverse effect of playing Pokémon Go is players' intense focus on their mobile screens, as a result of which players are unaware of events occurring in their surroundings in the real world. This danger also applies to other uses of mobile phones, but the experiential element and enjoyment from the game increases these risks for Pokémon Go players (Colley et al., 2017; Joseph \& Armstrong, 2016). As a result, various incidents involving injuries sustained while playing the game have been reported. The first report of this kind involved two youngsters who fell off a cliff while trying to catch a Pokémon that appeared near them. As the game's popularity rose, more game-related accidents were reported, including many accidents in which people were injured while driving. One man was reported as crashing his brother's car because he was playing the game while driving; a young woman, oblivious to her surroundings because she was playing the game, was hit by a car; and one man even caused a chain accident when he stopped his car in the middle of a highway in order to catch Pokémon (Abent, 2016). Additional adverse effects include increased risk of abduction, 
trespassing, violence, and cost, and as a result this game format poses specific threats to the safety and physical wellbeing of children (Serino et al., 2016).

In response to the large number of accidents, public pressure was put to bear on the game's developers, who responded by incorporating warnings not to drive while playing the game. In October 2016, an update to the game made it impossible to play when the GPS identifies that the player is moving above a specific speed.

Another aspect of the public and media pressure against the game is related to the privacy of players' information. Niantic was reported to have full access to players' Google accounts. The company closed this "privacy hole" within days but numerous accusations charged the game with collecting information about the players without their knowledge (de Souza e Silva, 2017; Hjorth \& Richardson, 2017).

The media and the public play a major role in triggering panics related to moral concerns and protection of the public order (Lim, 2013) through their extreme responses to new technologies that are considered to be threats to the existing public order (Buckingham \& Strandgaard Jensen, 2012; Cohen, 1972). It seems that the media's extensive engagement with Pokémon Go's dangers is a contemporary example of such moral panic.

Pokémon Go's dependence on a smart phone game application and players' ability to engage in the game while engaged in other everyday activities raise important issues related to players' second screening, which is the simultaneous use of multiple devices and screens.

\section{Second Screening}

The term "second screen" refers to the use of another screen - a smart phone, tablet etc. while watching TV. This activity is sometimes also referred to as "Multitasking Media" (Lee et al., 2018). In many cases, the action taken on the second screen is related to viewing, for example: comments on social networks about watching. This is what creates a kind of "social TV," that is, audience interaction (Giglietto \& Selva, 2014). In the present age, the phenomenon of second screening is gaining momentum and it is widely practiced (Giglietto \& Selva, 2014; Van Cauwenberge et al., 2014). Many have reported that they use a second screen to keep themselves busy while advertising, or watching less interesting content (Giglietto \& Selva, 2014).

\section{Uses and Gratifications}

The theoretical framework guiding this research is the uses and gratifications approach, which explains that communications consumers use various media and types of content to satisfy psychological and social needs (Ruggiero, 2000), and that the consumer's selection of specific contents and media is largely dictated by the consumer's social roles and pre-existing inclinations (Katz, Blumler \& Gurevitch, 1973). Studies have found that media consumers have multiple needs that are satisfied by media channels that offer specific platforms, content, technology broadcast formats, availability, accessibility, and other features ( $\mathrm{Haz} \& \mathrm{Katz}, 2000$ ). It is further argued that people are intelligent enough to identify their own needs and select media and content for consumption accordingly. As a result, people will consume more of what they want and what satisfies their needs (Wei, 2008).

The media selections a person makes are related to various motivations. That is to say, the medium and content that a person selects will vary to fulfill different needs, and are based on different motivations (Lin, 1999). In the era of multiple channels and technologies, uses and gratifications are becoming increasingly significant in consumers' selection of media and content, due to the availability of more options from which the consumer can choose (Wei, 2000).

Various media have been found to be associated with different needs. For example, a decision to consume radio and print newspapers is related to the satisfaction of cognitive needs, while consumption of television is related to the satisfaction of emotional needs ( $\mathrm{Haz} \& \mathrm{Katz}, 2000$ ). Adults' use of mobile phones is associated with a need for family and security, while use of mobile phones by teenagers is related to friendships (Wei, 2008). It has been found that the more people perceive their mobile phones as satisfying the need to pass the time and maintain contact with others, the more they also use their mobile phones to play interactive games while on route (Wei, 2008).

Video games can satisfy many needs for players. The main functions of video games are entertainment and escapism (Hou, 2011; Sherry et al., 2006), yet video games can also satisfy cognitive, emotional, social, and other needs. For 
example, it has been found that video games improve player's mood and allay anxieties. Moreover, games constitute an "alternative universe" in which plays can practice social experiences and improve their social skills (Granic et al., 2014). Escapism is an important need that such games satisfy. We will elaborate below on the literature regarding escapism.

\section{Escapism}

Escapism is a person's desire to escape from everyday worries and relax at the end of the day (Chang et al., 2018). Escapism distracts a person from reflecting on her real-life problems and allows her to "shut off" her brain by engaging in activities that require less or different kinds of thinking (Young et al., 2017). Escapism also allows one to avoid one's sense of loneliness (Chen \& Lu, 2016). Escapism has been found to be an important motivation for Internet use and one of the motivations of people who play various games, including online games (Chen \& Lu, 2016). The escapist element in games seems to be the gap between the game and reality, allowing players to escape their everyday life by immersing themselves in the reality of the game (Chang et al., 2018). Yet, it has been found that players who play video games for escapist motivations believe that the game environment is as real as real life (Bowditch et al., 2018).

Two types of escapism can be distinguished: passive escapism and active escapism. Passive escapism is characterized as third-person observation. That is to say, in passive escapism the individual is not an active participant in any action nor does she have an opportunity to interact with the escapist text or content. Television viewing is a prime example of passive escapism. In contrast, active escapism requires an individual's involvement, for example by controlling a character in a game (Jones et al., 2018). In contrast, "game culture" is considered an active, complex form of escapism that involves the actor in a game to varying degrees (Shaw, 2010).

Research on video games has found that escapism is associated with extensive weekly use by both genders. Players' use of a game increased the more the game satisfied their escapist motivations (Yee, 2006). Social video games that involve multiple players have also been found to constitute a form of escapism from stress, and that players play games less out of competitive motivations and more out of a desire to forget and escape from their everyday worries and concerns (Hou, 2011). Mobile technologies have also been found to function as a means for escapist activities with the goal of relaxing and escaping from one's problems (Smetaniuk, 2014).

The point of departure of the current research is the uses and gratifications approach, which assumes that media consumers select the media and the contents they consume based on the needs they wish to satisfy. Therefore, an examination of game players' motivations importantly allows us to better understand these needs. Moreover, an analysis of players' needs also sheds light on games' impact on players.

\section{Research Questions}

1. Based on Yee's model, what are players' unique motivations for playing the AR game Pokémon Go?

a. Does the game promote players' physical activity?

b. Is playing the AR game Pokémon Go motivated by a unique type of escapism?

\section{Method}

This research examined the motivations for playing Pokémon Go, using a qualitative research methodology. Interviews were conducted with 35 Pokémon Go players ( $85 \%$ male) who were identified on dedicated Pokémon Go forums and Facebook groups using purposive (judgmental) sampling. The range of ages is between 22 and 44 . The interviewees gave their consent to take part in the interviews. The questions were asked and answered in Hebrew and the answers were translated to English. The interviews were conducted face to face in a café in the vicinity of the interviewee's house. This is a non-probability sampling method yet is suitable in the case of a specific research population, which in this case comprises Pokémon Go players. The weakness of this sampling method is that the researcher cannot guarantee that the selected participants constitute a representative sample of the research population, especially since the respondents are active players of the game and take part in forums and Facebook groups.

Interviews were based on a semi-structured questionnaire. The questionnaire contained a list of questions yet allowed and encouraged deviations and adjustments. The idea underlying this type of interview is that it allows the researcher to explore specific topics of interest, yet allows interviewees to associate these topics to their own domains, experience, 
and views (Yonay \& Turin, 2000). In the interviews, background questions were posed first, to put interviewees at ease. Example background questions included:

How long have you been played AR games?

Have you played other online games in the past?

What game groups do you belong to and why did you choose these groups?

Interviewees were then asked the following questions:

What are your motivations for the game?

Why is it important for you to advance in the game?

Does the game cause you to go outside and become more familiar with your environment?

Does the game promote your physical activity?

Have you established any new relationships with other people as a result of playing the game?

When and where do you go to catch Pokémon?

Interview responses were analyzed using a qualitative thematic analysis in which interpretations, meanings, and generalizations were proposed for the phenomenon under investigation (Dushnik, 2011). Thematic analysis is performed by comparing the responses of various interviewees and identifying common patterns (Braun \& Clark, 2006; Dushnik, 2011), and therefore the researcher must be familiar with the subject matter of the materials obtained in the data collection phase (Braun \& Clark, 2006). The analysis is not, however, based exclusively on the researcher's interpretations, but is also based on the bodies of knowledge that are relevant to the research, of which the researcher has a command (Dushnik, 2011). The first phase in a thematic analysis focuses on the review and study of the interview transcripts. By arranging the transcripts of the responses to each question alongside each other and comparing them, the researcher identifies themes in the interview responses.

In this research, 35 Pokémon Go players were interviewed by a research assistant who participated in the development of the questionnaire and had extensive knowledge of the subject matter. The interviews were taped and transcribed by the research assistant. The chief investigator first listened to the taped interviews and then used the transcripts to identify and group common meanings and patterns into classes (Vaca, 2015).

\section{Results}

The current research was designed to gain an understanding of and define the unique motivations for playing AR games. The current research found that the most frequently reported motivations of game players in the literature, such as achievement, sociability, entertainment, and escapism, were also reported by Pokémon Go players. In addition, two motivations were identified and found to be unique for AR game players: (a) location-based escapism that is integrated into players' everyday activities, and (b) physical activity, which is first identified here as a motivation for game playing.

\section{Achievement}

The interviewees in the current study reported achievement and competition as the needs for playing Pokémon Go, in different degrees. Several interviewees stated that catching Pokémon was important to them and that they would invest various degrees of effort to catch them, as reflected in the following quote:

"It is very important to me to advance in the game and to capture a rare Pokémon. I can do it for hours in order to meet my friends' achievements." (Male, 19) 
Other interviewees however, mentioned that they invest in the game moderate efforts and do not leave their "comfort zone" to achieve the game goals:

"I do not blow the game out of proportions and do not invest special efforts to advance in the game." (Male, 26)

We also identified a downward trend in the motivations of longstanding players of the game. That is to say, players reported a high need for achievement when they commenced playing, but their need for achievement in the game declined over time as their enthusiasm for the game dropped.

"It's important, but in view of my current priorities I can't find time [to play].... Once, it was important to me. It's very dynamic, this game, in terms of the sacrifices I make for the game. Once I would not stop playing in order to reach a high ranking in gyms ... there is also this [desire] to match other players' levels: [if] everyone is at a certain level then you want to get there." (Male, 26)

"In the beginning, [it was very important for me to advance in the game]... At some point I understood the concept of the game and how to play... In the beginning I was into "topping" everyone else [but] when you're on top too long it starts to bore you." (Male, 24)

"When you first start playing the game you are very enthusiastic about the little details, but the more you advance the less relevant it becomes..." (Female, 23)

\section{Sociability}

The current research found that sociability, and especially teamwork, is one of the motivations for playing Pokémon Go. Many interviewees mentioned the recent innovations in the game, which requires large groups of players to arrive at sites, and the game's new challenges, such as Raids and taking over gyms, which leads to enjoyment and satisfaction based on teamwork.

Several players recounted that they play Pokémon Go with their friends and family members. For example, one interviewee stated that he searches for Pokémon with his wife, while another stated that he regularly looks for Pokémon with his son. A third interviewee said, "Incidentally I meet new [friends] - they are my friends for all intents and purposes, and I am dating someone as a result." However, this statement is rather unique since the current research found that players' interactions are brief and mainly focused on the game; Most players do not tend to share their personal experiences from their real lives with other players and they mainly talk with other players about things related to the world of the game. This is reflected in the following quotes:

"The friends are mainly around the game. The conversation is about the game. Sometimes we text on WhatsApp about the game but these are short conversations."

Another interviewee stated, "We met through the game and we talk mainly about the game."

The interviewees in the current study noted that the interactions that they developed as a result of playing Pokémon Go did not extend into the "real world," although some interviewees would have liked that:

"We got to know each other through the game and we talk only about the game. I personally tried to make conversations on different topics but they stuck to catching Pokémon and talked only about the game."

It should be noted that some interviewees stated that they play Pokémon Go in heterogeneous groups and therefore they are unable to develop deeper relationships with other players:

"I am 43. Yesterday I met people for a raid. There was a 60 year old man and another one with his $12-$ year-old daughter, and another boy who is $15 \ldots$ so, with a teenager, the game is the only thing I can talk about." (Male, 43) 


\section{Entertainment}

The current research found that Pokémon Go also satisfies players' need for enjoyment and their need for an escape from their everyday problems and reality. The interviewees described how Pokémon Go meshes with their other hobbies, and that they look forward to playing the game after they come home from work. As one interviewee stated,

"At the end of the day I like to hang out with my friends...I have a couple of friends who play the game so I like to go out and play with them..."

While a second interviewee summarized his feelings: "I just play because it's fun."

Many interviewees reported they gain intense enjoyment from "escaping reality."

As one of the interviewees mentioned, "I love the game because it helps me forget my problems." (Male, 36)

Another interviewee mentioned that "Playing Pokémon go is escaping reality and diving into a different world." (Male, 44)

Another aspect of the need for entertainment is distraction. The interviewees stated that players' immersion in the game distracts them from the time and space of their surroundings:

"You dive into the game and you can play for hours. You lose track of time." (Male, 36)

Another interviewee pointed out, "I sometimes get swept away in the game and spend hours playing instead of studying for tests." (Female, 23)

Some interviewees even mentioned that playing disorients them or others in a manner that leads to risky behaviors:

"I have friends that are so into the game that they cross the roads without looking around. They are so distracted that they are oblivious to their surroundings." (Male, 31)

\section{Location-Based Escapism Integrated Into Everyday Activities}

The interview materials indicate that engagement in Pokémon Go occurs concurrently with and even enhances everyday activities. As a result, we identify a new type of escapism that occurs within routine activities and ordinary multitasking. As one interviewee stated:

"I play Pokémon Go everywhere I go...I walk around and check...." (Male, 25)

Another interviewee stated that she plays the game when she goes out running:

"I go out for a run with it... and I stop my run in the middle to catch Pokémon." (Female, 30)

Another interviewee recounted that Pokémon Go serves as a means of escapism for him and his friends while they are engaged in other, including social, activities:

"I have some friends who play together so we hang out and go out and when we're in, let's say, a bar, I will open the game and play...." (Male, 32)

Pokémon Go thus constitutes a location-based form of escapism for players, which is also evident from the description given by the following interviewee:

"Whenever I have time, I open [the app], so that it stays in the background.... At work, or when walking the dog, or when I go out on a hike..." (Male, 36) 
Interviewees indicated that Pokémon Go functions as the backdrop to their everyday activities outside the home, and they play the game while going to the supermarket, meeting friends, etc. One interviewee explained why he felt the need to open the game while engaged in other activities:

"It helps me do the things I want to do and makes them less boring." (Male, 40)

\section{Physical Activity}

A positive effect that emerged from the interviews is that Pokémon Go encourages people to spend time outdoors and therefore promotes physical activity. Many interviewees reported that they considered physical activity to be one of the game's positive outcomes.

"Regarding sports - [the game] requires walking, it requires you to move around outside..." (Male, 38)

Interviewees stated that they play the game when they go out running or jogging, and that the game caused them to walk more. Other interviewees stated:

"I know people who the game helped to leave their house to take a walk, to get fit..." (Male, 32)

"It made me get out of the house more and be less of a couch-potato." (Male, 33)

Interviewees also described the long walks they started taking because of the game: "One thing that it caused [me to do] is.... walk more, I walk about 10 kilometers a day, so that the eggs can hatch." (Male, 27) and "We would go on pretty long walks ... and it really benefited me a lot...."(Male, 32)

Others stated that the game encouraged them to walk around their neighborhood and become familiar with their surroundings:

"It made me walk around a lot .... Look, the game came out a year ago, let's say that in the first year I would walk intensely for days on end. I was depressed because of personal issues, but this shook me up and brought me back to life, made me go out to play the game, and I would go out from morning until evening, sometimes from five in the afternoon until two in the morning." (Female, 32)

Another interviewee stated that when she moved, the game encouraged him to walk around and become familiar with his new neighborhood:

"When I moved into my new apartment, we walked around the area a lot, we got to know places, gyms..." (Male, 26)

In a similar spirit, an interviewee stated that when he played the game he learned about places in his neighborhood of which he was previously unaware:

"I discovered a lot of things [while playing], even about my own neighborhood and the neighborhoods in the vicinity. I've lived in my neighborhood more than 20 years and suddenly I discovered a veterans' memorial that I had no idea existed...." (Male, 34).

Table 1. Summary of Main Themes.

\begin{tabular}{llc}
\hline & Main motivations for playing Pokémon Go & Results (\%) \\
\hline 1 & Achievement based on varying degrees of effort & $79 \%$ \\
& Need for achievement declines over time & $44 \%$ \\
3 & Sociability mostly framed to interactions derived from the game & $42 \%$ \\
4 & Entertainment, 'escaping reality' and immersion & $67 \%$ \\
& Location-based escapism integrated into everyday activities. The game & $64 \%$ \\
\hline
\end{tabular}




\section{Discussion}

The current research examined the motivations for playing Pokémon Go, an AR mobile game, with reference to studies on motives and motivations for playing online games, video games, and other AR games. Identifying motivations for a game importantly allows us to understand the needs that the game satisfies. The uses and gratifications theory explains that people have different needs and consume media and technologies in a manner that satisfies these needs (Ruggiero, 2000; Sherry et al., 2006).

Based on the interviews conducted in the current research, Pokémon Go players' motivations for the game align with the diverse uses that have been found for video and AR game players and their needs for achievement, social interactions, escapism, and entertainment (Granic et al., 2014; Hou, 2011; Sherry et al., 2006). In addition, two new motivations for playing games were identified in the current study: location-based escapism and physical activity.

Interviewees in the current study reported that Pokémon Go satisfies the need for achievement and competition, to different degrees. This finding is consistent with findings of previous studies that focused on video and online games (Hou, 2011; Yang \& Liu, 2017; Yee, 2006). However, it was found that players' motivation for achievement declines over time. According to the uses and gratifications theory, which argues that people are intelligent enough to identify their own needs and select media and content for consumption accordingly (Wei, 2008), we assume that over time, Pokémon Go players will gradually seek alternative means for satisfying their need for achievement.

Pokémon Go was also found to satisfy players' need for social interaction. This finding is consistent with previous research that indicate that maintaining ties and investing in relationships with others is one of the motivations for playing online games (Yee, 2006), including Pokémon Go (Yang \& Liu, 2017). Interactions with family members and friends have been found to have a strong impact on players and influence their choice to continue playing a game over a long period (Rasche et al., 2017). The current research also found that sociability, and especially teamwork, is one of the motivations for playing Pokémon Go. The recent innovations in the game require a large group of players to arrive at sites, and new challenges added to the game lead to enjoyment and satisfaction based on teamwork. However, in line with previous findings (Ducheneaut \& Moore, 2004; Seay et al., 2004), the current research also found that most of the interactions that occur in the game are framed within the specific space and content of the game itself. Players typically do not tend to share their personal experiences from their real lives with other players and instead mainly talk with other players about things related to the world of the game.

Escapism is one of the dominant motivations for playing games, including video games (Hou, 2011; Sherry et al., 2006). Findings of the current research show that Pokémon Go constitutes a powerful means of escapism and entertainment. The interview materials indicate that engagement in Pokémon Go occurs concurrently with and even enhances everyday activities. Interviewees reported a high level of enjoyment from the game during leisure hours, and also viewed the game as a means of escape from other activities or as background to enhance the experience of other concurrent activities. The findings of this research thus expand the typology of escapism in the literature, adding another level to escapism. In addition to passive escapism and active escapism described in the literature, the current study identified a new level of escapism: mobile location-based escapism, which occurs within routine activities and ordinary multitasking. That is to say, players engage in Pokémon Go concurrently with other activities, and in this context Pokémon Go constitutes a means of escape even from activities performed outside the home, which in themselves constitute a means of satisfying escapism needs.

It may be assumed that motivation for this type of escapism will become more dominant in the selection of AR games over time, specifically in view of technological developments in AR that facilitate the use of a second screen while engaging in routine everyday activities. In the current study, interviewees reported that the game is integrated seamlessly into other everyday activities outside the home such as supermarket shopping and spending time with friends. AR games can be expected to increasingly satisfy escapist motivations concurrently with other activities. This trend is already evidenced by multiple contemporary examples of multitasking and second screening (Giglietto \& Selva, 2014; Van Cauwenberge et al., 2014). A classic example of second screening is the use of social media and WhatsApp concurrently with other activities. In the current research, we see that Pokémon Go also constitutes a means of escape to a second screen while performing other activities or during another activity, similarly to the findings of other studies that found that viewers used a second screen during commercials or during broadcasts of irrelevant contents (Giglietto \& Selva, 2014). The game's added value as a second screen is similar to the added value of the traditional medium of radio, which 
is typically consumed as a secondary medium while performing other activities such as driving, sports activities, housework, and cooking (Laor et al., 2017).

Spending time outside and engaging in physical activity also emerged as unique motivations for playing AR games. In the past, online games and computer games in general were characterized by a player's physical immersion in a closed room and by considerable immobility. In contrast, AR features require players' integration into the real world and therefore location-based game features compel players to leave their homes, which leads to physical activity. In the current research, players' expressed their satisfaction with the physical activities that the game induces. In the future, players may select AR games specifically for their capacity to motivate people to leave their homes and engage in physical activity.

The current research indicates that Pokémon Go players have multiple motivations for playing the game, and these motivations are consistent with the motivations identified in previous research and models. The game satisfies different needs for different players, primarily the need for escapism, social interaction, and challenging others. In the current research, Pokémon Go serves as a case study of mobile AR games. The main contribution of this research is the insight it offers on the use of the game as a means of active location-based escapism that is performed ordinarily, on an everyday basis, in all places. This consumption pattern is apparently part of the revolution of online and mobile information accessibility, and its contribution to society is the satisfaction for the need for highly available and accessible information, entertainment, and escapism.

The findings of this study highlight the insightful contributions of the uses and gratifications approach to the study of AR games. Today, Pokémon Go is merely a game but AR technologies are most likely to develop into location-based apps that provide real-time location-based information or other types of assistive data, anywhere and at any time, as a backdrop to other activities. It is conceivable that in the not-too-distant future, many games and services use AR to satisfy people's needs for information, entertainment, and escapism. Physical activity, one of the unique motivations for playing AR mobile games identified in this research, will also probably expand to other games played by people in countries where there is strong awareness of a healthy lifestyle that incorporates physical activity. In the future we can expect to see an increasing dependency on AR games to satisfy a variety of human needs.

\section{References}

Abent, E. (2016, July 15). Five Pokémon go accidents that stress the importance of paying attention. SlashGear. https://www.slashgear.com/five-Pokémon-go-accidents-that-stress-the-importance-of-paying-attention-15448441/

Alha, K., Koskinen, E., Paavilainen, J., \& Hamari, J. (2019). Why do people play location-based augmented reality games: A study on Pokémon Go. Computers in Human Behavior, 93, 114-122. https://doi.org/10.1016/j.chb.2018.12.008

Althoff, T., White, R. W., \& Horvitz, E. (2016). Influence of Pokémon Go on physical activity: Study and implications. Journal of Medical Internet Research, 18(12), Article e315. https://doi.org/10.2196/jmir.6759

Arbel, H., Lahman, D., Epstein, N., Kaufman, H., \& Kablinsky Ben Dor, D. (2011). למידה באמצעות משחקים [Learning through games]. Eureka, 32, 1-14.

Avouris, N., Sintoris, C. \& Yiannoutsou, N. (2013). Learning in the city through pervasive games. In The Hybrid City II: Subtle revolutions (pp.192-195). University of Athens.

Baranowski, T., \& Lyons, E. J. (2019). Scoping review of Pokémon Go: Comprehensive assessment of augmented reality for physical activity change. Games for Health Journal. Advance online publication.

https://doi.org/10.1089/g4h.2019.0034

Bartle, R. (1996). Hearts, clubs, diamonds, spades: Players who suit MUDs. The Journal of Virtual Environments, 1(1). http://mud.co.uk/richard/hcds.htm

Bowditch, L., Chapman, J., \& Naweed, A. (2018). Do coping strategies moderate the relationship between escapism and negative gaming outcomes in World of Warcraft (MMORPG) players? Computers in Human Behavior, 86, 69-76. https://doi.org/10.1016/j.chb.2018.04.030 
Braun, V., \& Clarke, V. (2006). Using thematic analysis in psychology. Qualitative research in psychology, 3(2), 77-101. http://dx.doi.org/10.1191/1478088706qp063oa

Buckingham, D., \& Strandgaard Jensen, H. (2012). Beyond "Media Panics": Reconceptualising public debates about children and media. Journal of Children and Media, 6(4), 413-429. https://doi.org/10.1080/17482798.2012.740415

Chang, S.-M., Hsieh, G. M. Y., \& Lin, S. S. J. (2018). The mediation effects of gaming motives between game involvement and problematic Internet use: Escapism, advancement and socializing. Computers \& Education, 122, 43-53.

https://doi.org/10.1016/j.compedu.2018.03.007

Chen, H.-J., \& Lu, J.-T. (2016). Clarifying the impact of social escapism in users' acceptance for online entertaining services-An extension of the technology acceptance model based on online karaoke television services users. Information Systems Management, 33(2), 141-153. https://doi.org/10.1080/10580530.2016.1155949

Clark, A. M., \& Clark, M. T. G. (2016). Pokémon Go and research: Qualitative, mixed methods research, and the supercomplexity of interventions. International Journal of Qualitative Methods, 15(1), 1-3.

https://doi.org/10.1177/1609406916667765

Cohen, S. (1972). Folk devils and moral panics. Routledge.

Colley, A., Thebault-Spieker, J., Lin, A. Y., Degraen, D., Fischman, B., Häkkilä, J., Kuehl, K., Nisi, V., Nunes, N. J., Wenig, N., Wenig, D., Hecht, B., \& Schöning, J. (2017). The geography of Pokémon Go: Beneficial and problematic effects on places and movement. In Proceedings of the 2017 CHI Conference on Human Factors in Computing Systems (pp. 11791192). ACM Press. https://doi.org/10.1145/3025453.3025495

Deleuze, G. (1988). Spinoza: Practical philosophy. City Lights Books.

de Souza e Silva, A. (2017). Pokémon Go as an HRG: Mobility, sociability, and surveillance in hybrid spaces. Mobile Media \& Communication, 5(1), 20-23. https://doi.org/10.1177/2050157916676232

Dorward, L. J., Mittermeier, J. C., Sandbrook, C., \& Spooner, F. (2017). Pokémon Go: Benefits, costs, and lessons for the conservation movement. Conservation Letters, 10(1), 160-165. https://doi.org/10.1111/conl.12326

Dushnik, L. (2011). ניתוח נתונים במחקר האיכותי: הצעה לארבעה עקרונות מנחים [Analysis in qualitative research: A proposal for four guiding principles]. Research Paths, 17, 137-143.

Ducheneaut, N., \& Moore, R. (2004). The social side of gaming: A study of interaction patterns in a massively multiplayer online game. In J. Herbsleb \& G. Olson (Eds.), Proceedings of the 2004 ACM Conference on Computer Supported Cooperative Work (pp. 360-369). ACM Press.

Ducheneaut, N., Yee, N., Nickell, E., \& Moore, R. (2006). "Alone together?": Exploring the social dynamics of massively multiplayer online games. In R. Grinter, T. Rodden, P. Aoki, E. Cutrell, R. Jeffries, \& G. Olson (Eds.), Proceedings of the SIGCHI Conference on Human Factors in Computing Systems (pp. 407-416). ACM Press.

Fernando, G. (2016, July 13). How Pokémon Go is helping people with social anxiety and depression. News.com.au: Technology. http://www.news.com.au/technology/homeentertainment/gaming/how-pokemon-go-is-helpingpeoplewith-social-anxiety-and-depression/newsstory/bdf546cd7979d0c11480fcb596e61538

Giddings, S. (2017). Pokémon Go as distributed imagination. Mobile Media \& Communication, 5(1), 59-62.

https://doi.org/10.1177/2050157916677866

Giglietto, F., \& Selva, D. (2014). Second screen and participation: A content analysis on a full season dataset of tweets. Journal of Communication, 64(2), 260-277. https://doi.org/10.1111/jcom.12085 
Gotow, J. B., Zienkiewicz, K., White, J., \& Schmidt, D. C. (2010). Addressing challenges with augmented reality applications on smartphones. In Y. Cai, T. Magedanz, M. Li, J. Xia, \& C. Giannelli (Eds.), Lecture notes of the institute for computer sciences, social informatics and telecommunications engineering (Vol. 48, pp. 129-143). Heidelberg.

Granic, I., Lobel, A., \& Engels, R. C. M. E. (2014). The benefits of playing video games. American Psychologist, 69(1), 6678. https://doi.org/10.1037/a0034857

Hamari, J., Malik, A., Koski, J., \& Johri, A. (2019). Uses and gratifications of Pokémon Go: Why do people play mobile location-based augmented reality games? International Journal of Human-Computer Interaction, 35(9), 804-819. https://doi.org/10.1080/10447318.2018.1497115

Hanson, M. (2017, May 24). How to download and play Pokémon Go right now. TechRadar. https://www.techradar.com/how-to/gaming/how-to-download-and-play-pokemon-go-right-now-1324484

Haz, H., \& Katz, A. (2000). The role of the mass media in Israel 1970-1990. In A. Katz et al. (Eds), Leisure culture in Israel: Changes in the patterns of cultural activities 1970-1990 (pp. 311-340). Open University.

Hjorth, L., \& Richardson, I. (2017). Pokémon Go: Mobile media play, place-making, and the digital wayfarer. Mobile Media \& Communication, 5(1), 3-14. https://doi.org/10.1177/2050157916680015

Hou, J. (2011). Uses and gratifications of social games: Blending social networking and game play. First Monday, 16(7). https://doi.org/10.5210/fm.v16i7.3517

Howe, K. B., Suharlim, C., Ueda, P., Howe, D., Kawachi, I., \& Rimm, E. B. (2016). Gotta catch 'em all! Pokémon Go and physical activity among young adults: Difference in differences study. BMJ, 355(8086), Article i6270.

https://doi.org/10.1136/bmj.i6270

Jones, S., Cronin, J., \& Piacentini, M. G. (2018). Mapping the extended frontiers of escapism: Binge-watching and hyperdiegetic exploration. Journal of Marketing Management, 34(5-6), 497-508.

https://doi.org/10.1080/0267257X.2018.1477818

Joseph, B., \& Armstrong, D. G. (2016). Potential perils of peri-Pokémon perambulation: The dark reality of augmented reality? Oxford Medical Case Reports, 2016(10), 265-266. https://doi.org/10.1093/omcr/omw080

Katz, E., Blumler, J. G., \& Gurevitch, M. (1973). Uses and gratifications research. The Public Opinion Quarterly, 37(4), 509523. https://doi.org/10.1086/268109

Keogh, B. (2017). Pokémon go, the novelty of nostalgia, and the ubiquity of the smartphone. Mobile Media \& Communication, 5(1), 38-41. https://doi.org/10.1177/2050157916678025

Kjeldskov, J., \& Paay, J. (2007). Augmenting the city with fiction: fictional requirements for mobile guides. In K. Cheverst and B. Schmidt-Belz (Eds.), Proceedings of the 5th workshop on HCl in Mobile Guides, Mobile HCl 2007 (pp. 15-20). ACM Press.

Landi, M. (2016, December 1). Pokémon Go app named as the most popular game of 2016 on Google Play. The Mirror. http://www.mirror.co.uk/tech/Pokémon-go-app-named-most-9375173

Laor, T., Galily, Y., \& Tamir, I. (2017). Radio presence in online platforms in Israel. Israel Affairs, 23(5), 951-969. https://doi.org/10.1080/13537121.2017.1345420

LeBlanc, A. G., \& Chaput, J.-P. (2017). Pokémon Go: A game changer for the physical inactivity crisis? Preventive Medicine, 101, 235-237. https://doi.org/10.1016/j.ypmed.2016.11.012

Lee, S., Baek, J., \& Han, G. (2018). Effects of using a second-screen application on attention, learning, and user experience in an educational content. Interactive Learning Environments, 26(3), 289-307.

https://doi.org/10.1080/10494820.2017.1324494 
Lim, S. S. (2013). On mobile communication and youth "deviance": Beyond moral, media and mobile panics. Mobile Media \& Communication, 1(1), 96-101. https://doi.org/10.1177/2050157912459503

Lin, C. A. (1999). Uses and gratifications. In G. Stone, M. Singletary, \& V. P. Richmond (Eds.), Clarifying communication theories: A hands-on approach (pp. 199-208). lowa State University Press.

Magerkurth, C., Cheok, A. D., Mandryk, R. L., \& Nilsen, T. (2005). Pervasive games: Bringing computer entertainment back to the real world. ACM Computers in Entertainment, 3(3), Article 4A. https://doi.org/10.1145/1077246.1077257

Nelson, R. (2016, July 12). Mobile users are spending more time in Pokémon Go than Facebook. Sensor Tower. https://sensortower.com/blog/pokemon-go-usage-data

Nigg, C. R., Mateo, D. J., \& An, J. (2017). Pokémon Go may increase physical activity and decrease sedentary behaviors. American Journal of Public Health, 107(1), 37-38. https://doi.org/10.2105/AJPH.2016.303532

Pyae, A., \& Potter, L. E. (2016, November). A player engagement model for an augmented reality game: A case of Pokémon Go. In Proceedings of the 28th Australian Conference on Computer-Human Interaction (pp. 11-15). ACM.

Rasche, P., Schlomann, A., \& Mertens, A. (2017). Who is still playing Pokémon Go? A Web-based survey. JMIR Serious Games, 5(2), Article e7. http://doi.org/10.2196/games.7197

Rashid, O., Mullins, I., Coulton, P., \& Edwards, R. (2006). Extending cyberspace: Location based games using cellular phones. ACM Computers in Entertainment, 4(1), Article 3C. https://doi.org/10.1145/1111293.1111302

Ruggiero, T. E. (2000). Uses and gratifications theory in the 21st century. Mass Communication and Society, 3(1), 3-37. https://doi.org/10.1207/S15327825MCS0301_02

Saban, M. (1991). משחקי לוח קדומים בארץ ישראל [Board games in Canaan during the Early Bronze and Middle Bronze A periods, and the source of the Egyptian game of Senet]. Israel Exploration Society, 233.

Seay, A. F., Jerome, W. J., Lee, K. S., \& Kraut, R. E. (2004). Project massive: a study of online gaming communities. In E. Dykstra-Erickson and M. Tscheligi (Eds.), CHI EA '04: CHI '04: Extended Abstracts on Human Factors in Computing Systems (pp. 1421-1424). ACM Press.

Serino, M., Cordrey, K., McLaughlin, L., \& Milanaik, R. L. (2016). Pokémon Go and augmented virtual reality games: A cautionary commentary for parents and pediatricians. Current Opinion in Pediatrics, 28(5), 673-677.

https://doi.org/10.1097/MOP.0000000000000409

Shaw, A. (2010). What is video game culture? Cultural studies and game studies. Games and Culture, 5(4), 403-424. https://doi.org/10.1177/1555412009360414

Sherry, J. L., Lucas, K., Greenberg, B. S., \& Lachlan, K. (2006). Video game uses and gratifications as predictors of use and game preference. In P. Vorderer \& J. Bryant (Eds.), Playing video games: Motives, responses, and consequences (pp. 213-224). Lawrence Erlbaum Associates.

Smetaniuk, P. (2014). A preliminary investigation into the prevalence and prediction of problematic cell phone use. Journal of Behavioral Addictions, 3(1), 41-53. https://doi.org/10.1556/JBA.3.2014.004

Statt, N. (2016, July 22). Pokémon Go breaks App Store record for most first-week downloads in history. The Verge. https://www.theverge.com/2016/7/22/12258874/Pokémon-go-apple-ios-app-store-record-most-downloads

Tekinbaş, K. S. (2017). Afraid to roam: The unlevel playing field of Pokémon Go. Mobile Media \& Communication, 5(1), 34-37. https://doi.org/10.1177/2050157916677865

The Marker (2016, July 13). הזמנים בכל ביותר הגדול למשחקהסלולר הפך גו פוקימון :שהושק אחרי שבוע [One week after its launch: Pokémon Go is the biggest mobile game of all times]. http://www.themarker.com/wallstreet/1.3006315 
Vaca, R. A. (2015). Young leaders' mindset toward mature employees': A qualitative transcendental phenomenological study [Doctoral dissertation, University of Phoenix].

Van Cauwenberge, A., Schaap, G., \& van Roy, R. (2014). "TV no longer commands our full attention": Effects of secondscreen viewing and task relevance on cognitive load and learning from news. Computers in Human Behavior, 38, 100109. https://doi.org/10.1016/j.chb.2014.05.021

Wei, R. (2008). Motivations for using the mobile phone for mass communications and entertainment. Telematics and Informatics, 25(1), 36-46. https://doi.org/10.1016/j.tele.2006.03.001

Williams, D., Yee, N., \& Caplan, S. E. (2008). Who plays, how much, and why? Debunking the stereotypical gamer profile. Journal of Computer-Mediated Communication, 13(4), 993-1018. https://doi.org/10.1111/j.1083-

6101.2008.00428.x

Xian, Y., Xu, H., Xu, H., Liang, L., Hernandez, A. F., Wang, T. Y., \& Peterson, E. D. (2017). An initial evaluation of the impact of Pokémon GO on physical activity. Journal of the American Heart Association, 6(5), Article e005341.

https://doi.org/10.1161/JAHA.116.005341

Yang, C. C., \& Liu, D. (2017). Motives matter: Motives for playing Pokémon Go and implications for wellbeing. Cyberpsychology, Behavior, and Social Networking, 20(1), 52-57. https://doi.org/10.1089/cyber.2016.0562

Yee, N. (2006). Motivations for play in online games. CyberPsychology \& Behavior, 9(6), 772-775.

https://doi.org/10.1089/cpb.2006.9.772

Yehoshua, Y., \& Parish, Y. (2014). בלמידה משחק שילוב - בתחפושת לימודי חומר הוא משחק [Games are learning materials in disguise - Integrating games in learning]. Sha'anan Religious Academic College of Education.

http://www.levladaat.org/data/upl/SitePages/843-sRedirTo.pdf

Yonay, Y. and Torin, A. (2000). כיצד נשים. חוות רומנים רומנטיים : ליהנות מטקסט רע [Enjoying a bad text: how do women enjoy romantic novels]. Politics, Communication and Society, 4, 187-157.

Young, N. L., Kuss, D. J., Griffiths, M. D., \& Howard, C. J. (2017). Passive Facebook use, Facebook addiction, and associations with escapism: An experimental vignette study. Computers in Human Behavior, 71, $24-31$. https://doi.org/10.1016/j.chb.2017.01.039

Zach, F. J., \& Tussyadiah, I. P. (2017). To catch them all-the (un) intended consequences of Pokémon GO on mobility, consumption, and wellbeing. In R. Schegg \& B. Stangl (Eds.), Information and Communication Technologies in Tourism 2017 (pp. 217-227). Springer. 


\section{Correspondence to:}

Tal Laor

Ariel University

65 Ramat Hagolan st.

Ariel 40700

Israel

Email: tallaor10(at)gmail.com

Editorial record: First submission received on February 10, 2019. Revisions received on October 27, 2019, November 7, 2019 and February 20, 2020. Accepted for publication on February 20, 2020.

Editor in charge: Kristian Daneback

\section{About Author}

Tal Laor, Ph.D., is a researcher in the field of media, a lecturer and Head of Radio, Broadcast and Content Production Studies at Ariel University, Israel. A fellow at the Institute for New Media Research, Society and Politics. A founding member of the School of Communication at Ariel University. He received his Ph.D. in communication [Summa Cum Laude] at Paris 8 University, France. He is an expert in developing and implementing innovative and relevant media concepts to the new media. 